Voix et Images

voixetimages

\title{
Une mort dans le siècle
}

Patrick Nicol

Volume 17, numéro 1 (49), automne 1991

Louky Bersianik

URI : https://id.erudit.org/iderudit/200951ar

DOI : https://doi.org/10.7202/200951ar

Aller au sommaire du numéro

Éditeur(s)

Université du Québec à Montréal

\section{ISSN}

0318-9201 (imprimé)

1705-933X (numérique)

Découvrir la revue

\section{Citer cet article}

Nicol, P. (1991). Une mort dans le siècle. Voix et Images, 17(1), 153-154.

https://doi.org/10.7202/200951ar d'utilisation que vous pouvez consulter en ligne.

https://apropos.erudit.org/fr/usagers/politique-dutilisation/ 


\section{Une mort dans le siècle}

\section{par Patrick Nicol, Université de Sherbrooke}

Le contact avec la mort nous amènera toujours à parler de la vie. La vie fragile devant la violence de la maladie; la vie individuelle inscrite dans lá grande mouvance d'une époque. Ceux qui restent se sentent le besoin de parler: Vautour, maintenant que tu n'es plus, je te recrée par les trüs de mon crâne. C'est un collage sadique de tes paroles et de leur sismographie qui rendra compte de ton passage parmi moi. (p. 33) Voilà donc le projet qui anime Christian Mistral au moment d'écrire Vautour ${ }^{1}$. Auteur et narrateur confondus saluent le disparu et l'élèvent à un nouveau rang, encensant jusqu'à ses petitesses, comme il est de mise dans ce genre de circonstance.

C'est alternativement à un narrataire inconnu puis à Vautour luii-même que s'adressent les quatre parties du roman, alternance qui permet le double registre du chant funèbre et de la chronique des événements. La mort entre en scène dès la première partie; c'est ensuite la rencontre des deux colocataires de fortune, appelés à devenir amis, qui nous est relatée. La structure et la mise en place sont habiles: le lecteur, au seuil de la troisième partie, est captivé par ce qui s'annonce être un livre à la fois grave et exubérant.

Vautour est musicien, il se croit du talent. On l'imagine maigre et vaguement blond, alternant les cigarettes et les joints comme autant de pied de nez à sa chair menacée (p. 17), autant de sursis arrachés. Car il a le cœur faible et sa mort prochaine plane au-dessus de lui comme l'oiseau dont il emprunté le nom.

Les plus belles pages nous viennent du rapport troublant qui s'établit entre la vulnérabilité du corps et la démesure du rêve. D'un côté, il y a ce cour perforé dans un torse étrangement bombé puis, tout autour, il y a cette Amérique qui se construit par l'image qu'elle donne d'elle-même. Le rêve atteint la taille d'un continent alors que le corps se limite souvent à peu de choses:

A l'hôpital; il était comme tout le monde, un problème nu dans "une jaquette de toile qui ne ferme pas en arrière, il était VAUG61031718, un numéro de série rappelé par le manufacturier, temporairement retiré du marché. (p. 20)

Et puis voilà que le rêve lui-même est douteux: Ton Amérique n'existait même pas et personne n'osait te le dire. (p. 52) Était-il faux de croire qu'il reste au moins le rock et le hockey pour donner une chance aux pauvres (p. 141)? Finalement, oui. Et qui de mieux placé pour le savoir que ce Christian Mistral, colocataire de Vautour et écrivain de son état? Il en a fait le constat dans son premier roman, 
Vamp, qui sort des presses quelque temps avant la mort du musicien. Le succès est immédiat, les journalistes s'intéressent à lui, le rêve que chérit Vautour est à la portée de Mistral mais il n'y croit pas.

Le projet d'écriture se trouve alors perverti. Ce qui promettait d'être un discours sur l'autre se transforme en récit autobiographique. Dans la troisième partie, qui est de loin la plus longue, nous assistons à la naissance médiatique de Christian Mistral, l'écrivain, et à quelquesunes de ses frasques dans un certain Montréal littéraire. L'émotion et l'intérêt suscités par les premières parties ne renaitront que pour les quelques pages de la fin. On reconnaîtra, à peine masquées, des références à la revue Stop (Taxi dans le livre) et à [d]'hystériques héros fin-de-millénaire (p. 90), écrivains et amis de l'auteur. Une fois fini le jeu du décodage (qui est qui ?), l'intérêt du lecteur va diminuant.

Autrement intéressante est cette tentative de cerner les contours flous de ce qu'on appelle, à défaut de mieux, "l'air du temps". En vidant le contenu disparate de sa mémoire, en recopiant le menu d'un restaurant ou en lançant quelques bribes d'un savoir anecdotique, Mistral réussit à nous restituer une partie de ce mélange de souvenirs et d'impressions qui constitue notre bagage commun. L'effet recherché n'est pas toujours atteint et ces tentatives pourront agacer; j'y ai pour ma part trouvé un plaisir certain. Ces morceaux épars constituent peut-être la meilleure part de la chronique contemporaine que Mistral tente de faire:

Je me souviens de l'assassinat de Pierre Laporte. Je me souviens que Vautour a manqué d'eau chaude pour.son troisième bain d'hier. Je me souviens de grand-père les yeux rivés sur Lawrence Welk à la télé... (p. 91)

Malheureusement, l'auteur se sent obligé de s'en expliquer et on ne sait trop si c'est pour provoquer ou pour s'excuser qu'il fait dire à Vautour: Tu prends 'n'importe quelle cochonnerie et t'en fais de la littérature. (p. 42) C'est peut-être parce qu'il s'exagère son audace qu'il agit ainsi ou alors c'est qu'il sous-estime son lecteur...

Une chose est sûre: Vautour est un texte qui renvoie constamment à lui-même en se justifiant et en essayant de parer les critiques: ils vont dire qu'en fait, c'est à moi que j'écris, ou bien que je profite de ce que t'as passé l'arme à gauche pour me faire du capital verbogène (p. 37). De tels passages déçoivent parce que nous étions, prêts à prendre le texte tel quel, sans explication, sans sommation.

Si on se surprend à souhaiter que Mistral accepte d'entrer dans son sujet et cesse de se regarder écrire, c'est qu'à l'occasion il peut être très justè et parfois presque troublant.

1 Christian Mistral, Vautour, Montréal, XYZ, 1990, 154 p. (Romanichels). 